\title{
$\mathbf{R}$

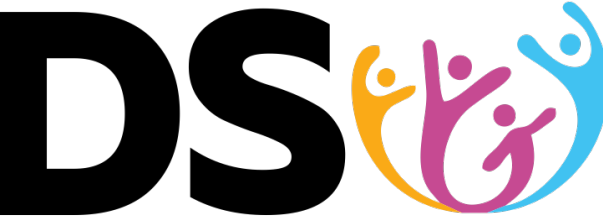

Revista Desenvolvimento Social

\section{ACOLHIMENTO FAMILIAR, ARTICULAÇÃO DE REDE E REINTEGRAÇÃO FAMILIAR: REFLEXÕES A PARTIR DA PRÁTICA ${ }^{1}$}

\author{
Julia Matinatto Salvagni² \\ Regina Lúcia Sucupira Pedroza ${ }^{3}$
}

Resumo: Este artigo discute a importância da garantia do direito a convivência familiar e comunitária de crianças e adolescentes no contexto das Políticas de Assistência Social, em especial nas situações de afastamento do convívio familiar devido à medida protetiva de acolhimento. A partir dessa contextualização, discute-se os resquícios e impactos do histórico menorista do Brasil, mesmo que com a instauração da doutrina da proteção integral e, nesse sentido, como possibilidade de romper com a hegemonia do aparelho institucional da proteção à infância, o investimento em outras modalidades de acolhimento, como o Serviço de Acolhimento em Família Acolhedora (SFA). Coloca-se o SFA como via para a garantia do direito à convivência familiar e comunitária, bem como suas potencialidades para trabalhar de forma efetiva a articulação de rede, enquanto instrumento dos processos de reintegração familiar. Nessa perspectiva, é descrito um caso que elucida os principais pontos da discussão proposta e a partir dele, reflexões a respeito da temática estudada.

Palavras-chave: Acolhimento familiar. Reintegração familiar. Rede Socioassistencial. Política de assistência social. Direitos da Criança e do Adolescente.

\section{FOSTER CARE, SOCIAL NETWORKS AND FAMILY REINTEGRATION: REFLECTING THROUGH PRACTICES.}

\begin{abstract}
This article discusses the importance of guaranteeing the right to family and community life for children and adolescents in the context of Social Assistance Policies, especially in situations of distancing from their original family life due to protective measures. Based on this context, the remnants and impacts of the minorist history of Brazil are discussed, even with the establishment of the doctrine of full protection and, in this sense, as a possibility of breaking with the hegemony of the institutional apparatus of child protection, investment in other forms of care, such as the Foster Care Service. The Foster Care Service is placed to guarantee the right to family and community coexistence, as well as its potential to make network articulation effective, as a way of working in family reintegration processes. From this perspective, a case is described that elucidates the main points of the proposed discussion and based on it, reflections on the topic studied.
\end{abstract}

\footnotetext{
${ }^{1} \mathrm{O}$ presente artigo compõe o trabalho de pesquisa de doutorado de uma das autoras, aprovado pelo Comitê de Ética e Pesquisa em Ciências Humanas da Universidade de Brasília.

${ }^{2}$ Aluna de doutorado do Programa de Pós-graduação em Psicologia Escolar e do Desenvolvimento do Instituto de Psicologia da Universidade de Brasília. ORCID: https://orcid.org/0000-0001-5281-9657. Email: jusalvagni@gmail.com.

3 Professora Associada da Universidade de Brasília no Instituto de Psicologia. ORCID: https://orcid.org/0000-0003-2251-5040. E-mail: rpedroza@unb.br.
} 
Keywords: Foster Care. Family Reintegration. Social Assistance Network. Social Assistance Policy. Children's Rights

\section{ACOGIEMENTO FAMILIAR, ARTICULACIÓN DE LA RED Y REINTEGRACIÓN FAMILIAR: REFLEXIONES DE LA PRÁCTICA}

Resumen: En este artículo se analiza la importancia de garantizar el derecho a la vida familiar y comunitaria de los niños y adolescentes en el contexto de las Políticas de Asistencia Social, especialmente en situaciones de alejamiento de la vida familiar por la medida de protección del acogimiento familiar. Con base en este contexto, se discuten los remanentes e impactos de la historia minorista de Brasil, incluso con el establecimiento de la doctrina de la protección plena $y$, en este sentido, como una posibilidad de ruptura con la hegemonía del aparato institucional de protección de la infancia, inversión en otras formas de acogimiento, como el Servicio de Acogida Familiar (SFA). La SFA se plantea como una vía para garantizar el derecho a la convivencia familiar y comunitaria, así como su potencial para trabajar eficazmente la articulación de la red, como una forma de trabajar en los procesos de reinserción familiar. Desde esta perspectiva, se describe un caso que dilucida los puntos principales de la discusión propuesta y, a partir de ella, reflexiones sobre el tema estudiado.

Palabras-clave: Acogimiento familiar. Reinserción familiar. Red de Asistencia Social. Política de asistencia social. Derechos de la niñez y la adolescencia.

\section{INTRODUÇÃO}

Conviver em família e comunidade é um direito fundamental das crianças e adolescentes, garantido na norma constitucional brasileira, e no Estatuto da Criança e do Adolescente (ECA). Segundo o Plano Nacional de Promoção, Proteção e Defesa do Direito de Crianças e Adolescentes à Convivência Familiar e Comunitária (PNCFC), documento elaborado de forma democrática e participativa com representantes do governo e sociedade civil, a convivência familiar e comunitária, enquanto direito e como fator de promoção do desenvolvimento integral, foi durante muito tempo negligenciada pela política de atendimento à infância. O PNCFC demarca a ela um lugar de destaque na política pública ao buscar:

(...)romper com a cultura da institucionalização de crianças e adolescentes e ao fortalecer o paradigma da proteção integral e da preservação dos vínculos familiares e comunitários preconizados pelo Estatuto da Criança e do Adolescente. A manutenção dos vínculos familiares e comunitários fundamentais para a estruturação das crianças e adolescentes como sujeitos e cidadãos - está diretamente relacionada ao investimento nas políticas públicas de atenção à família. (BRASIL, 2006, p. 13). 
Este artigo irá discutir as possibilidades de atuação dos serviços de acolhimento familiar (SFA) enquanto ponto de articulação da rede socioassistencial visando efetivar os processos de reintegração familiar de crianças e adolescentes acolhidos. O acolhimento é uma medida excepcional e provisória, prevista no ECA, com o objetivo de garantir a proteção integral quando outras medidas protetivas se mostram ineficazes e o afastamento familiar torna-se a única opção. Tal excepcionalidade é ponto de destaque, uma vez que o direito a conviver no seio familiar de origem é garantido pela mesma norma legal, e assegurado constitucionalmente. Entretanto, é importante delinear que o debate sobre a convivência familiar e comunitária deve ser pauta constante e sempre em atualização.

A perspectiva da centralidade familiar enquanto núcleo de defesa e proteção para o cuidado da infância ganha destaque nas últimas décadas, e enfrenta cotidianamente entraves e resistências advindos de uma forte trajetória de segregação e institucionalização como demarcadores históricos da atenção à infância em nosso país. Ainda hoje, mesmo com o paradigma da proteção integral, um dos pilares do ECA, é possível observar nas práticas cotidianas de atores diversos do Sistema de Garantia de Direitos da Criança e do Adolescente (SGDCA), heranças da doutrina da situação irregular que estava em voga e era sustentada pelos Códigos de Menores (BRASIL, 1927; BRASIL, 1979).

As práticas sociais em curso até a década de 1990 eram marcadas pela culpabilização e responsabilização de crianças (e suas famílias) pelas situações de risco social, violência e violações de direitos que viviam. O Estado respondia a esses cenários por meio de mecanismos disciplinatórios e de segregação (GARCIA, LIMA, 2020; OLIVEIRA et al, 2018). Havia uma preocupação com a manutenção de uma ordem social, que se sobrepunha a um possível olhar para o bem-estar das crianças, adolescentes e suas famílias. Há inclusive, uma distinção nesse sentido, entre quem eram as crianças e quem eram os menores, sendo esses últimos aqueles compreendidos enquanto aqueles que estavam em "situação irregular" ou apresentavam risco à referida ordem social.

Assim, tem-se durante quatro séculos de história brasileira, mesmo que com diferenças importantes, modelos que se instauraram e se fortaleceram com foco em equipamentos institucionais que atuavam através do controle social. Garcia e Lima (2020) reforçam que a "prática da institucionalização de crianças pobres como 
alternativa à convivência familiar e comunitária foi mantida de modo regular e acrítico até o fim da década de 1980, favorecendo a diferença de concepção e de tratamento entre crianças em relação a menores" (p.70).

Na década de 1980, com a efervescência dos movimentos sociais em prol da redemocratização, e de denúncias diversas acerca das atrocidades e violências vividas intramuros em instituições de atendimento à "menores", ganha força o debate a respeito da garantia de direitos da infância. A materialização do dever do estado, da família e da sociedade em garantir a proteção integral da criança comparece no artigo 227 da Constituição Federal (Brasil, 1988), posteriormente regulamentado pelo ECA. Segundo Arantes (2004), o cerne do debate que culminou no referido artigo é que:

(...) a questão da criança no Brasil não é uma questão médica ou policial. É neste sentido que as proposições do Estatuto trazem à cena, em primeiro lugar e antes de quaisquer outras considerações, a questão da cidadania para todas as crianças e jovens. Não se pode pensar em modelos de atendimento, em medidas de proteção e em medidas sócio-educativas que não tenham a guiá-las este imperativo. Tratar as crianças e os adolescentes como sujeitos de direitos, não lhes negar a humanidade e a dignidade, constituir com eles uma perspectiva de futuro: eis o único caminho, se queremos construir a paz social (p.164).

Porém, destaca-se que a criação da norma jurídica não garante sua aplicabilidade e concretização. Nesse sentido, o arcabouço legal que precedeu o ECA tinha uma característica diferente, uma vez que emergia a partir de práticas já instituídas. Ou seja, refletiam em suas propostas o status quo de uma determinada época. O ECA, por sua vez, se constitui a partir de reflexões e críticas acerca das práticas em curso, enquanto possibilidade de operar mudanças em um sistema que se apresentava violador, ao invés de protetivo, bem como segregador e ineficiente em muitos aspectos. Isso faz com que se observe, ainda hoje, distâncias entre o texto legal e as ações cotidianas, e uma aproximação destas, em algumas situações, com o ordenamento jurídico anterior. Frisamos que a lei não é autoaplicável, é necessário que seus operadores sedimentem as mudanças que ela propõe (GARCIA; LIMA, 2020; NASCIMENTO, 2012; VALENTE,2013).

Desta maneira, GARCIA (2018) chama a atenção para a existência em nosso ordenamento social de um ideal de modelo de família, ainda não superado, que foi 
instaurado pela reafirmação de um discurso de segregação social e controle, e sustentado pela reprodução de valores perpetrados socialmente enquanto morais e positivos por instituições como o Estado e a Igreja. Ao longo dos últimos séculos da história brasileira, as famílias pobres eram assistidas dentro de um paradigma higienista de intervenção estatal. A autora destaca que se observava: "certa antinomia que separava as famílias da sociedade, o espaço de dentro e o de fora, o mundo da produção e da reprodução, caracterizando o domínio privado como dotado de valores próprios, modeladores do que se viveria externamente na vida pública (p.33)".

Assim, por mais que o ECA, e demais normativas que o sucedem, versem sobre o direito da criança e do adolescente - e sobre atuações conexas ao tema, especialmente no que se refere ao trabalho social com famílias (como é o caso da Lei Orgânica de Assistência Social) - e se oponham a essa tradição, complexificando a compreensão acerca dos modelos e formas de convivência familiar, bem como reafirmem a centralidade do superior interesse da criança e do adolescente, e seu protagonismo, ainda é possível observar nas práticas e ações do poder público, um forte viés social, de raça e gênero. Por exemplo, segundo o Diagnóstico Sobre o Sistema Nacional de Adoção e Acolhimento (CONSELHO NACIONAL DE JUSTIÇA, 2021) 64,3\% das crianças e adolescentes em medida protetiva de acolhimento no Brasil são pardas e pretas. Além disso, apesar de a prática e o cotidiano de atuação nesse campo demonstrarem que as crianças/adolescentes acolhidos são de famílias em situação de pobreza ou extrema pobreza, há uma escassez de dados acerca da condição socioeconômica das famílias cujos filhos foram afastados de sua convivência.

Outra herança histórica bastante marcante nas políticas públicas que atuam junto à infância é sua natureza institucional. Desde o período colonial, o Brasil deu continuidade ao modelo Europeu, no qual as crianças e adolescentes, à época considerados vadios e marginais, eram encaminhados para grandes instituições. Inicialmente estas eram geridas pela Igreja e tinham como discurso de base uma lógica caritativa. Progressivamente o Estado, sob a égide de uma "cientificamente" orientada, passa a tomar conta dessa pauta, ainda de forma irrisória e distante da consolidação de uma política pública que visasse a garantia de direitos sociais. Dessa forma, dando continuidade ao modelo de grandes instituições, dentro de um paradigma caritativo, punitivista e correcional (RIZZINI, RIZZINI, 2004). Havia pouco, ou nenhum, investimento 
em um olhar individualizado e afetivo direcionado ao público atendido, e os esforços em um planejamento técnico de ações e acompanhamento também eram restritos.

Entretanto, desde a promulgação da Constituição Federal (BRASIL, 1988), e posteriormente do ECA, as diretrizes da atuação na área da criança e do adolescente estão em constante transformação. Isso abrange a política de acolhimento de crianças e adolescentes, que organiza a execução dos serviços que recebem a faixa etária de zero a 18 incompletos anos afastada judicialmente do convívio familiar. Nesse sentido, há na norma jurídica o estabelecimento de um discurso que zela pela excepcionalidade do afastamento familiar, pela não culpabilização da pobreza (ECA, art. 23) e pela premência dos esforços nos processos de reintegração, uma vez que a criança tenha sido afastada judicialmente (BRASIL, 1990). Pontos que se distanciam consideravelmente das práticas até então instituídas, demasiadamente marcadas pela culpabilização das famílias e da pobreza.

Nascimento (2012), entretanto, pontua que:

No cotidiano da consolidação dessa legislação, a família pobre foi ganhando um novo estatuto: família negligente, categorização que passa a justificar a intervenção estatal e a continuidade da retirada de crianças e adolescentes de suas famílias. Em poucas palavras: não se retira por pobreza, mas por negligência, e são os pobres os considerados negligentes. (...) as intervenções jurídicas e sociais continuam a punir os pobres, por exemplo, com a destituição do poder familiar, com abrigamentos apressados, com a imposição de normas de conduta (p. 40).

Isso aponta para a necessidade de manutenção de uma postura crítica a respeito da intervenção estatal no cotidiano das famílias. Mastroiani (2018) destaca que o contraste entre o discurso legal e a prática das medidas protetivas é significante, especialmente quando se considera que é necessário que se desenhem ações direcionadas à família, tanto no sentido de prevenir a medida protetiva de acolhimento, como no de superar as motivações que ensejaram a separação da criança/adolescente de seu núcleo de origem. Há, portanto, a previsão de que Estado e sociedade devem atuar também no fortalecimento e proteção das famílias cujos filhos estão acolhidos. Ou seja, agir em prol do superior interesse da criança e do adolescente é indissociável do estabelecimento de um trabalho de intervenção em seu sistema familiar. Para isso é necessário, segundo o autor, ultrapassar a cultura institucional assistencialista, 
investindo em dinâmicas que corroborem e favoreçam o protagonismo familiar, substituindo a culpabilização das famílias por perspectivas de responsabilização e construção de autonomia.

O paradigma da proteção integral requer que se estabeleçam vias de comunicação mais fluídas e efetivas entre os diversos atores envolvidos no SGDCA. As ações devem ser coordenadas de forma que as famílias sejam atendidas e compreendidas em sua complexidade, e que cada órgão envolvido possa agir dentro de seu escopo técnico, mas sem perder a visão geral daquilo que ocorre. Esse alinhamento dialógico é importante para as crianças e adolescentes serem vistas e protegidas de potenciais situações de risco e, concomitantemente, suas famílias tenham a possibilidade de se reorganizar. Evitando ao máximo processos extremos como os de destituição do poder familiar que findam com os direitos parentais e com a possibilidade de retomada dos vínculos cotidianos entre crianças/adolescentes e suas famílias (MASTROIANI, 2018).

Os movimentos sociais e a percepção da necessidade de implementação cotidiana das políticas instauradas pelo ECA ganha força nos anos 2000. Nesse período, além do PNCFC, há outros avanços importantes na legislação e na política da infância e juventude. Destacamos as Orientações Técnicas: Serviços de Acolhimento para Crianças e Adolescentes - OT (BRASIL, 2009) e as Lei 12.010 de 03 de agosto de 2009 e 13.257 de 8 de março de 2016, que trazem alterações importantes no ECA.

Um ponto destes documentos é que inserem no discurso oficial o serviço de família acolhedora e outras iniciativas de valorização de atuações mais individualizadas no contexto do acolhimento, como os programas de apadrinhamento afetivo. Até 2009, havia poucos serviços de acolhimento na modalidade familiar, porém, o reconhecimento de sua existência e importância no ordenamento jurídico e na organização da gestão da assistência social fomentam o debate sobre o tema e dão credibilidade e maior segurança para que o SGDCA invista em modelos de execução além do institucional.

A publicação das OT fortalece os processos de reordenamento do sistema de acolhimento no país, amparadas posteriormente pela Resolução no 23 do Conselho Nacional de Assistência Social (CNAS, 2013). Há um corpo significativo de estudos sobre o impacto negativo da institucionalização no desenvolvimento de crianças e 
adolescentes, conforme apontam Diniz, Assis e Souza (2018). Elas retomam autores clássicos da psicologia como Spitz, Wallon e Bowlby para discutir a necessidade de qualificar e profissionalizar o cuidado institucional, dando destaque ao papel do afeto e do vínculo na vida dos seres humanos.

Segundo Baptista e Zamora (2018), o processo de reordenamento da rede de acolhimento contempla essa visão ao objetivar redesenhar e repensar as práticas em voga, consolidando modelos que levassem em consideração as normativas e a transformação de práticas antigas, mas ainda vigentes, ou seja, ultrapassar uma mudança de nomenclatura e operar uma transformação de fato. Segundo as autoras:

Reordenar é reorganizar, adequar, recompor, trabalhar de forma matriciada entre diversos atores do SGD para integralidade das ações. Remete a novas formas, novos pensamentos, ações conjuntas, partilhadas, enfim, a implementação de uma Rede de Atendimento. Visa investir em capacitação de recursos humanos, trabalhar em sistema de cofinanciamento e privilegiar outras ações em rede, priorizando a perspectiva do planejamento e monitoramento dos trabalhos. Ademais, esse novo movimento deseja modificar situações de vulnerabilidade por meio de atendimento e acompanhamento. Preconizam-se públicos menores, investimento em acessibilidade e adequação da infraestrutura (p. 8).

Wendt et al (2018) atentam para a importância dessa reconstrução identitária das instituições de acolhimento, de forma que elas não estejam isoladas em si mesmas e se afastem de práticas análogas às marcas de uma instituição total. Sair de uma posição de perpetrar exclusão para um movimento de promoção de cuidado comunitário seria a grande mudança de chave para a efetivação do processo de reordenamento. Além disso, é necessário cada vez mais que a gama de serviços ofertados seja diversa e contemple as diferentes demandas do público atendido.

\section{ALGUMAS CONSIDERAÇÕES SOBRE O SERVIÇO DE ACOLHIMENTO FAMILIAR.}

O SFA, previsto no artigo 101 do ECA, em seu inciso VIII (BRASIL, 1990), consiste em proporcionar o acolhimento de crianças afastadas judicialmente do convívio familiar em casas de famílias da sociedade civil, que são inscritas, capacitadas, habilitadas e acompanhadas pela equipe técnica do serviço de acolhimento. Essas famílias não possuem vínculos familiares com as crianças e adolescentes acolhidos e não podem 
estar cadastradas no Sistema Nacional de Adoção e Acolhimento, logo não objetivam adotar as crianças/adolescentes que acolhem. Trata-se de um acolhimento temporário no qual a família cuidará da criança/adolescente pelo período que durar a medida judicial, ao passo que a equipe técnica do serviço realiza o trabalho psicossocial relacionado aos encaminhamentos necessários a cada caso.

O SFA é uma alternativa à institucionalização, seu diferencial é a possibilidade de ofertar cuidado e atenção individualizados, em ambiente familiar, podendo propiciar a construção de novos vínculos afetivos - protetivos e de qualidade - bem como a oportunidade de ampliar o repertório de convivência e cuidados cotidianos da criança/adolescente. Estar em família acolhedora oportuniza que o dia a dia com o acolhido seja conduzido em um ritmo que respeite e considere as demandas e temporalidades do acolhido, levando em conta os hábitos e rotina da família que acolhe. A atenção a essa relação e como ela favorece o desenvolvimento da criança confere novos contornos ao trabalho da equipe técnica, que nesta modalidade não se ocupa da dinâmica institucional.

O ECA, em seu artigo $34, \S 1$ versa que incluir crianças e adolescentes em acolhimento familiar deve ter preferência ao acolhimento institucional, presando sempre pela excepcionalidade e caráter temporário da medida protetiva de acolhimento (BRASIL, 1990). A inclusão desta precedência no texto legal se dá em 2009, através das alterações feitas pela lei 12.010, que corrobora com a defesa da importância de um olhar individualizado à criança e ao adolescente feita pelo PNCFC. O plano retoma estudos clássicos da psicologia que falam sobre a importância dos cuidados continuados, afetivos e de qualidade para o desenvolvimento infantil, em especial na primeira infância. Segundo o PNCFC (2006):

Tanto a imposição do limite, da autoridade e da realidade, quanto o cuidado e a afetividade são fundamentais para a constituição da subjetividade e desenvolvimento das habilidades necessárias à vida em comunidade. Assim, as experiências vividas na família tornarão gradativamente a criança e o adolescente capazes de se sentirem amados, de cuidar, se preocupar e amar o outro, de se responsabilizar por suas próprias ações e sentimentos. Estas vivências são importantes para que se sintam aceitos também nos círculos cada vez mais amplos que passarão a integrar ao longo do desenvolvimento da socialização e da autonomia (p.30). 
Além de estar em família acolhedora ser um fator protetivo, há de se destacar a importância na execução desta política da corresponsabilização da sociedade civil pelo zelo e garantia dos direitos da criança e do adolescente, como preconizado pela constituição federal (BRASIL, 1988). Ser família acolhedora não é uma atividade laboral, apesar de existirem iniciativas em território nacional com a profissionalização de famílias acolhedoras. A experiência no Brasil é majoritariamente de famílias da sociedade civil que atuam sem nenhum tipo de vínculo trabalhista. Destaca-se aqui que reconhecemos a necessidade de ampliar a discussão sobre a profissionalização, bem como sobre essa atuação ser ou não considerada voluntária, o que historicamente pode ser associado ao assistencialismo. As famílias acolhedoras são preparadas e acompanhadas pelas equipes do serviço e são a ela referenciadas, para que possam exercer esta função.

As famílias acolhedoras compõem, através da vinculação ao SFA, a rede de serviços do SGDCA, buscando a proteção integral da infância. Fazem isso ao abrir espaço em sua casa e seu cotidiano para ocupar o papel de guardiãs legais, mesmo que temporárias, de quem acolhem. Há um compromisso com o respeito aos costumes, crenças, vivências culturais e hábitos de cada um, em uma troca constante de experiências, cuidado e respeito. Cabe a família acolhedora, quando possível, também investir na reconstrução dos vínculos afetivos e sociais dos acolhidos e viabilizar a eles experiências comunitárias (BAPTISTA, DARÓS, ZAMORA, 2019).

Cuidar, proteger e amar as crianças e adolescentes que acolhem relaciona-se, de certa maneira, aos acolhedores se abrirem para serem facilitadores tanto do processo de adaptação ao acolhimento, quanto do processo de saída do SFA. No caso do encerramento da medida protetiva, colaborar com essa saída envolve dialogar com a equipe técnica acerca das possibilidades de reintegração, ou nos processos de adoção, de forma a ser ponte para essas transições junto às crianças e adolescentes. Isso envolve uma postura colaborativa e atenta aos próprios julgamentos e preconceitos, em especial acerca das motivações do acolhimento (BAPTISTA, DARÓS, ZAMORA, 2019; FERNADES JACOBINA, LEMOS DE PAIVA, 2020; VALENTE, 2013). 
A saída do SFA pode ocorrer por vias distintas: reintegração ${ }^{4}$ à família nuclear ou extensa, adoção, transferência de serviço, evasão ou desacolhimento pela maioridade. Cada uma dessas ações precisa ser refletida e planejada, levando em conta as vivências, demandas, afetos e condições de cada acolhido.

Para que isso seja viável, o processo de preparação e formação das famílias acolhedoras é um ponto chave. É necessário que haja da parte dessas famílias interesse, disponibilidade e compreensão das próprias motivações em participar do serviço. Em contrapartida, as equipes dos serviços de acolhimento devem implicar-se em realizar avaliação psicossocial de forma técnica e comprometida no que concerne as famílias que pretendem acolher. É ímpar alinhamento dos pré-requisitos, habilidades e competências para acolher, e a disponibilização de conteúdos e espaços de reflexão sobre temas relevantes para a execução do acolhimento, bem como sobre as condições e a realidade das crianças/adolescentes acolhidos em nosso país.

Esses pontos possibilitam refletir sobre uma formatação horizontalizada dos papeis dentro do SFA, em contraposição ao que geralmente se observa nos acolhimentos institucionais. Em contextos institucionais é comum nos depararmos com hierarquias, especialmente na organização das funções e atribuições: dirigentes, coordenadores, técnicos e cuidadores ocupam espaços institucionais que impactam e dialogam com o cuidado cotidiano dos acolhidos. Ao mesmo tempo que o dirigente está no lugar de guardião legal, quem ocupa o espaço de referência cotidiana com os acolhidos são as cuidadoras sociais, e intermediando essas relações está o corpo técnico, que assume diferentes responsabilidades, inclusive a da comunicação com o sistema de justiça e com o SGDCA. Espera-se que isso produza atravessamentos diversos sobre o cuidado da criança, bem como sobre o entendimento desse processo e a sua condução.

Já nos SFAs há um compartilhamento - inclusive do ponto de vista legal ao se pensar na correlação entre a guia de acolhimento e o termo de guarda - da responsabilidade e dos cuidados com a criança/adolescente (DE OLIVEIRA AVELINO, BARRETO, 2015). A família acolhedora se ocupa do cotidiano, dos hábitos, da rotina com

\footnotetext{
${ }^{4}$ O documento Diretrizes para reintegração familiar de crianças e adolescentes (DELAP \& WEDGE, 2016) traz importantes considerações sobre a utilização dos termos reintegração e reunificação, e reflexões acerca desses processos.
} 
os acolhidos, ao passo que a equipe técnica se empenha no estudo psicossocial dos casos e no apoio e orientação da família acolhedora, sempre com foco no superior interesse da criança. Essas duas pontas de atuação são dialéticas, interdependentes: o bom andamento técnico depende da confiança no cuidado dispensado à criança na família acolhedora e na compreensão e partilha acerca desse dia a dia. Da mesma forma que uma vinculação saudável, construída no contexto da relação da criança/adolescente com essa família, só é possível na medida que se compreenda e dialogue sobre os encaminhamentos da situação daquela criança.

Discute-se a consolidação de um cenário compartilhado de olhares, percepções e vínculos no qual o protagonista é sempre a criança/adolescente. Essa costura permite espaço de escuta e valorização da história de cada acolhido, do respeito às suas peculiaridades e à sua forma de estar e se colocar no mundo. Isso pode ser concretizado tanto com um bebê, ao se observar e respeitar seu ritmo, suas demandas e as maneiras como se manifesta, como para um adolescente, ao garantir seu espaço de fala e expressão a respeito dos encaminhamentos a serem realizados acerca se sua própria história.

Um dos desdobramentos desta troca é a possibilidade de ampliar, qualificar e otimizar o tempo e o investimento das equipes técnicas dos SFAs no trabalho social com as famílias de origem, possibilitando a construção de um estudo técnico de qualidade, com o maior envolvimento e diálogo com a rede de proteção de referência no território da família de origem, o que alimentará e subsidiará o olhar do sistema de justiça a respeito das possibilidades de atuação. A própria natureza do serviço, que tem uma maior flexibilidade, por não precisar se ocupar das rotinas comuns e de outros aspectos intrínsecos à uma vivência institucional, confere à atuação da equipe técnica uma ampliação das possibilidades de atuação extramuros.

Além disso, a especificidade que se dá na relação das famílias acolhedoras com cada criança/adolescente oferece uma riqueza de elementos sobre como a condução técnica e o andamento de cada caso impacta o desenvolvimento e o bem-estar das crianças e/ou dos adolescentes. É possível, por exemplo, a partir da relação das famílias acolhedoras com os acolhidos lançar um olhar atento para como os acolhidos ficam após cada visita da família de origem, se isso tem desdobramentos em seu comportamento, se acarreta mudanças na rotina de sono, alimentação, entre outros. A partir dessas 
observações os encaminhamentos podem ser pensados e repensados, tanto em relação aos seus objetivos, como à temporalidade das ações. Investir em transições suaves é importante no contexto das medidas de acolhimento, tanto institucional como familiar, mas especialmente favorecido neste último, por meio destas vivências.

Nesse sentido, Baptista, Zamora e Bittencourt (2017) pontuam que:

A possibilidade de confiar em alguém viabilizará a oportunidade de separarse posteriormente e de ocupar um lugar de forma inteira para constituir-se como sujeito. O tempo em que o amadurecimento se dá é o tempo de cada criança e a plasticidade com que cada um assimila as mudanças ambientais, assim como a maneira de agir e reagir diante das trocas, variam em cada indivíduo (p. 67).

As autoras trazem que viver em um espaço que proporcione cuidados e proteção contínuos e suficientemente bons, incidem e contribuem para que os acolhidos possam constituir-se como sujeitos de uma forma saudável, atravessada por vínculos e afetividade. A família acolhedora ocupa uma posição em que tem maiores condições de contribuir para a reconstrução e ressignificação das histórias por ligar-se a cada acolhido de forma única. Isso confere respeito à individualidade e a compreensão de que os acolhimentos são singulares. Mesmo que haja aproximações entre as narrativas e trajetórias, elas nunca serão as mesmas. O acolhimento familiar acalenta e aconchega quem está acolhido e ensina muito a quem acolhe. Confere à política pública da infância o lugar de se discutir e defender o vínculo afetivo enquanto instrumento de trabalho.

Por fim, a estrutura do SFA, ao propiciar o foco maior em cada criança/adolescente, amplifica as possibilidades de ação com as famílias de origem, uma vez que a proximidade com cada acolhido é também uma intimidade maior com sua história, e consequentemente com as narrativas familiares. A equipe técnica pode abrir um canal próximo de diálogo com a família de origem, o que possibilita a construção da compreensão das motivações do acolhimento, e, com as potencialidades e desafios de cada família, o que tem repercussão nas possibilidades de investir-se (ou não) nos processos de reintegração familiar, de uma maneira segura e protetiva.

Nakamura (2019) destaca a importância de se compreender e investir nessas relações com a família de origem, inclusive nos casos em que se ocorre a destituição do poder familiar, uma vez que a compreensão da criança e do adolescente a respeito desse 
processo se dá em um tempo próprio, e que os afetos e a vinculação com essa família que será destituída não atendem ou correspondem aos desdobramentos do processo judicial. Assim, a família acolhedora pode constituir para a criança um lugar de confiança e elaboração em relação a esse luto.

Apesar dos ganhos proporcionados pelo acolhimento familiar, é importante destacar que essa modalidade ainda corresponde a percentual pequeno em território nacional, de forma que é ímpar investir na divulgação e no debate acerca de seus benefícios.

\section{ARTICULAÇÃO DE REDE E REINTEGRAÇÃO FAMILIAR}

De Oliveira Avelino e Barreto (2015) problematizam que em ambas modalidades de acolhimento, a garantia da convivência familiar e comunitária dos acolhidos se mostra como desafio central dos atores envolvidos no SGDCA. Isso porque, a execução de ações comprometidas com esse objetivo é de natureza complexa, e envolve a percepção dos diversos segmentos envolvidos (famílias, técnicos, poder judiciário, entre outros), bem como as condições e o contexto, geralmente bastante fragilizados, das famílias de origem, tal qual a ordem e a gravidade da violação que ensejou a medida protetiva.

Segundo a Tipificação Nacional dos Serviços Socioassistenciais (BRASIL, 2014), um dos objetivos do SFA é apoiar o retorno da criança e do adolescente à família de origem. Para que se efetivem as ações necessárias a esse objetivo demanda-se compreender o que é preciso para viabilizar esse retorno de forma cuidadosa e protetiva. O primeiro passo é identificar quem são os atores que compõe a rede socioassistencial de referência daquele núcleo, o que foi realizado até aquele momento e quais os profissionais e equipamentos que precisam se envolver para garantir que uma atuação efetiva se estabeleça com aquela família, de forma a possibilitar o retorno da criança/adolescente ao seio familiar, ou esgotar todas as possibilidades de retorno ao núcleo de origem antes qualquer outro encaminhamento.

Investir em um trabalho voltado para a possibilidade de retorno da criança/adolescente à sua família envolve analisar os motivos que culminaram no afastamento do convívio familiar. Apesar de o acolhimento ser uma medida judicial, de 
maneira geral, o que a desencadeia são situações ocorridas no território da criança/adolescente e acompanhadas por um ou mais órgãos da rede de serviços socioassistenciais (conselho tutelar, Centro de Referência de Assistência Social, Centro de Saúde, escola, entre outros). Para a realização de um trabalho efetivo durante a medida de acolhimento é importante uma articulação profícua entre esses órgãos e o sistema de justiça, em especial uma comunicação fluida entre os serviços que atuam no caso e as equipes interprofissionais da VIJ.

O olhar e as concepções da equipe técnica do SFA acerca das famílias de origem e das situações que geraram o acolhimento refletem na condução das ações a serem delineadas e no diálogo estabelecido com os atores diversos do SGDCA. Ao falarmos de famílias cujas crianças/adolescentes estão acolhidas há uma gama extensa de fatores como a pobreza, violências estruturais, dificuldades em exercer o cuidado cotidiano, que podem ganhar nuances distintas, sendo inclusive agravados, por concepções sociais negativas acerca das famílias e suas capacidades. A equipe técnica precisa ter escuta atenta de suas próprias leituras sobre os casos acompanhados, para que imagens sociais negativas não incidam em revitimizações e culpabilizações das famílias e isso venha a diminuir o investimento no trabalho social a realizar. Estamos, enquanto seres sociais, suscetíveis a responder e reproduzir padrões que podem fomentar discursos de incompetência das famílias (PATIAS, GARCIA, DELL'AGLIO, 2016).

Os estereótipos sociais refletidos em famílias que possuem filhos acolhidos podem enrijecer imagens e compreensões de risco, gerando viéses acerca das dificuldades e desafios ao invés de investimento nas possibilidades e potencialidades de transformação, em especial das situações adversas e de possíveis cenários de violência. Além disso, tais preconceitos podem recair nas relações estabelecidas com as crianças/adolescentes e dificultar de alguma maneira sua inserção comunitária e a relação com os acolhedores.

Outro ponto que se relaciona à estereotipia sob a qual algumas famílias podem ser vistas, é a importância de se ultrapassar os modelos tradicionais de família ao desenhar o planejamento das ações voltadas à reintegração. O formato pai, mãe e filhos muitas vezes não condiz com as circunstâncias postas e não se configura como uma resposta viável às tentativas de atuação. É importante vislumbrar outras formas de construção de vínculos, que podem vir a ser mais salutares e fortalecedores, como a 
partir da figura de tios, irmãos, avós, padrinhos e madrinhas. (PATIAS, GARCIA, DELL'AGLIO, 2016).

Investir nesses outros formatos perpassa a compreensão de que o cuidado comunitário é profícuo e vantajoso às crianças/adolescentes e suas famílias. A existência de redes sociais ampara e fortalece as potencialidades das famílias, sendo tanto preventivas como promotoras de bem-estar para os núcleos em questão.

Sanícola (2008) debate as redes sociais enquanto malhas, que podem ser densas ou não, e que se compõe por pontos diversos, conectados entre si e recheados por relações bastante distintas de aliança, disputas, tensões, contraposições. Para ela, as redes sociais são configurações de relações e se dividem em rede primária, que é composta pela família e relações afetivas; e rede secundária estabelecida por lócus institucionais e organizações que atuam em prol do bem-estar e da garantia de direitos e cidadania. De certa forma, as redes primárias relacionam-se à esfera do pertencimento e da identidade, enquanto as secundárias vinculam-se à garantia da seguridade social.

Nesse sentido, Dos Santos Lopes e Dal Pra (2020) frisam que compor a rede de um sujeito ou família diz respeito a estabelecer confiança e articulações diversas entre seus membros, em arranjos recíprocos de apoio e diálogo. E, nessa troca dialética possibilitar a transformação das realidades. Ademais, o investimento nas relações afetivas e interpessoais nos contextos de proteção é ímpar, uma vez que, a princípio, apenas quando as relações estabelecidas em nível primário não sustentam as demandas e necessidades de um determinado sujeito ou grupo que se faz necessária a atuação da rede secundária para garantir a proteção social.

Apesar de terem lugares distintos de atuação, mais vinculados aos afetos estabelecidos ou à ação social do Estado, as diferentes redes sociais se conectam e comunicam, e entre elas se estabelece (além de uma interlocução direta e explicita) o trânsito de valores, crenças, medos e expectativas. A equipe do SFA passará a compor essa rede, em nível secundário e a família acolhedora poderá compor - sempre a depender de cada caso - a rede primária. Posto o objetivo comum entre os participantes, a priori o retorno da criança/adolescente, os próximos passos irão demonstrar as convergências e divergências no entendimento das situações. Gonçalves e Guará (2010) demarcam que dentre os muitos desafios para a implementação de um trabalho de rede consistente está a atuação por meio de uma lógica democrática e 
horizontalizada, que poderá garantir o respeito a cada um dos envolvidos e a articulação dialogada das ações a serem executadas.

Trabalhar em uma perspectiva de articulação de rede (afetiva e socioassistencial) é uma maneira de investir na corresponsabilização dos atores, valorizar seus papeis e atribuições individuais e compartilhar a gestão e os resultados de cada caso trabalhado. Essa modalidade de atuação evita que a família seja vista de forma fragmentada e isolada pelos serviços do território e amplia a efetividade dos encaminhamentos a partir de uma visão complexa das situações. O acolhimento de uma criança/adolescente demarca um cenário que demanda cuidados e atenção às situações que ocorrem no núcleo familiar atingido pela medida. Pressupõe-se, devido à excepcionalidade do acolhimento, que tal núcleo já deveria estar sendo atendido de maneira sistemática pelos serviços de seu território, mas muitas vezes o que o ocorre é que o afastamento da criança gera visibilidade a determinadas situações.

Logo, a articulação da rede compõe um processo de acompanhamento psicossocial que está entre as atribuições da equipe técnica do SFA. Garcia (2018) aponta que o trabalho social com famílias é composto por ações diversas, complexas e complementares, de forma que o alcance e solidez do que é realizado relaciona-se a maneira como as iniciativas de cada ponto da rede se entrelaçam. A falta de diálogo e consonância dos encaminhamentos pode incorrer em uma precarização do acompanhamento, devido à fragmentação das ações que compõe o plano de atendimento de uma determinada família (GARCIA, 2018).

Há indicativos na rede de acolhimento sobre a descontinuidade ou a não efetivação de uma atuação sistêmica, por exemplo, o desacolhimento por maioridade, onde a saída do adolescente não necessariamente ocorre em função de um processo de acompanhamento efetivo; e, também, a existência de acolhimentos de longa permanência, mesmo com o mapeamento de vínculos e de disponibilidade da família em aderir aos encaminhamentos realizados. Segundo Aguiar, Martins e Rosa (2019) esses exemplos indicam impasses na consolidação de uma rede socioassistencial reordenada, e que isso muitas vezes relaciona-se à manutenção, mesmo que residual, de uma lógica de segregação e punição como via interventiva nas camadas mais pobres e vulneráveis da sociedade. 
Implicar esforços nos processos de reintegração familiar é, de certa forma, andar na contramão dessa lógica. Reintegrar é investir em vinculações e possibilitar que famílias se vejam e sejam vistas a partir da sua capacidade de (re)organização e transformação, tanto da maneira como se relacionam, como do contexto à sua volta. Não significa apenas responsabilizar uma família por sua independência, mas construir conjuntamente a ela possibilidades para a consolidação de uma vida autônoma, na qual seria viável amplificar seus potenciais, e admitir suas fragilidades, contando com apoio sempre que se fizer necessário. Dessa maneira, propõe-se uma lógica comunitária de suporte mútuo e reciprocidade ao invés de um paradigma de isolamento e autossuficiência. Esse pensamento, que a família precisa se bastar, ou "caminhar com as próprias pernas" é atrelado ao já referido modelo idealizado de família, que atende a ideais capitalistas e de produção mercadológica.

O trabalho de reintegração deve ser iniciado com a deflagração do acolhimento. A maneira como a equipe do SFA estabelece as primeiras comunicações com a família de origem impacta na forma como essa família pode vir a aderir, ou não, aos encaminhamentos sugeridos. Muitas famílias chegam fragilizadas e estigmatizadas pela retirada da criança/adolescente e enxergam, em alguns casos, a equipe técnica como continuidade do poder público que atuou nessa retirada. Por isso, é importante garantir que essas pessoas sejam escutadas em suas dores e indignações, e pontuar que o SFA é um espaço de proteção da criança, mas também tratará de forma respeitosa e zelosa a família.

Nesse processo de acolhida da família é possível estabelecer relações de confiança, na qual se abrem espaço para reflexões e considerações sobre as violações de direito que culminaram no acolhimento, tal qual, sobre o desejo e a disponibilidade da família em compreender a medida protetiva e trabalhar junto à equipe e demais atores da rede para viabilizar o retorno da criança/adolescente. Para algumas famílias, o afastamento é um elemento que aumenta o contexto de fragilidade e é importante que a equipe esteja próxima para orientar e apoiar os núcleos demonstrando que há vias para ultrapassar a situação vivenciada de forma integrada e coletiva.

Além disso, as famílias acolhedoras têm um papel importante nos processos de reintegração, uma vez que fazem a ponte cotidiana dos acolhidos com os demais envolvidos no processo. A reintegração, como discutido, é um processo e não uma ação 
isolada. Deve ser construída de forma gradativa, buscando prover segurança para proceder com a consolidação do retorno à família. O acolhimento rompe com os vínculos cotidianos com a família de origem, e a possibilidade de retorno pode ser tanto à nuclear, como à extensa. Em ambos os cenários o fortalecimento e a confiança nos vínculos precisam ser focos do trabalho. Proporcionar visitas, espaços ampliados de convivência, participação da família de origem em aspectos diversos da vida da criança/adolescente (saúde, educação, entre outros) são importantes estratégias de atuação nesse sentido (BRASIL, 2009).

A família acolhedora participa desse processo observando e dando o contorno necessário após as visitas das crianças à suas famílias, tendo atitude e falas positivas e apoiadoras acerca desses encontros, demonstrando receptividade e abertura para dialogar sobre medos e inseguranças apresentados pela criança. Isso requer diálogo entre família acolhedora e equipe técnica, para que dúvidas e inseguranças sejam dirimidas. Dessa forma, o acolhido pode sentir-se pertencente à sua família, sabendo que não há entre os adultos em sua vida disputas ou concorrências, pelo contrário, há cooperação e cumplicidade.

Da mesma forma que essa parceria entre família acolhedora, família de origem e equipe gera segurança afetiva para os acolhidos, a sedimentação do trabalho em rede confere eficácia, efetividade e maior apropriação acerca dos encaminhamentos dos diversos atores da rede. Constituir espaços de troca e compartilhamento a respeito dos casos empodera as equipes e auxilia a delinear etapas a serem seguidas na consolidação da reintegração. Além disso, assim como a saída da criança do núcleo de origem é disruptiva, o retorno, se não for conduzido com cautela e cuidado, também pode ser. Portanto, é imprescindível que o plano de reintegração contemple ações de continuidade de acompanhamento e atendimento do núcleo familiar, para além do encerramento da medida. Dessa forma, se constroem espaços de garantia de direitos e fortalecimento de vínculos comunitários e familiares. A rede socioassistencial sai de um lugar histórico de cobrança e culpabilização e pode efetivar-se enquanto espaço de cuidado, proteção e promoção de bem-estar.

Para ilustrar as discussões propostas, trazemos um relato de caso de reintegração familiar, de um bebê que esteve em família acolhedora, ilustrando alguns 
pontos acerca do cotidiano do trabalho de articulação de redes no processo de reintegração, seus entraves e possibilidades.

\section{O ACOMPANHAMENTO DE MAIARA E RAFAEL: O SFA ENQUANTO ESPAÇO DE GARANTIA DE DIREITOS.}

Maiara ${ }^{5}$ é uma mulher indígena, de aproximadamente 50 anos. Mora em uma região de periferia, tem 11 filhos, dos quais 4 moram com ela. É mãe solo. Sua filha Jaci, 19 anos, desde o início de sua adolescência tem crises psicóticas severas, nas quais apresenta considerável desorganização psíquica e momentos de alucinações, engravidou e deu à luz a Rafael. Até o parto, a família não acreditava na gestação, se mantendo na crença que o discurso da jovem era fruto de suas alucinações. Ao entrar em trabalho de parto, Jaci teve uma forte crise. Ato contínuo ao nascimento de Rafael, foi encaminhada para internação psiquiátrica e Maiara foi contatada pela equipe da maternidade.

Maiara é uma das líderes da comunidade em que vive, entretanto tinha uma relação conflituosa com o Conselho Tutelar (CT) ao qual é referenciada. A equipe do serviço social da maternidade entrou em contato com o referido órgão para assegurar que a liberação de Rafael para a avó materna era de fato protetiva. O CT se manifestou contrário à liberação do bebê à Maiara, alegando que ela bebia abusivamente. A liberação do bebê foi feita para a filha mais velha de Maiara, Joana.

Apesar disso, quem assumiu os cuidados cotidianos com o bebê foi Maiara, uma vez que Joana trabalhava fora, em uma rotina bastante intensa e o único arranjo possível para ambas é que Maiara cuidasse do neto, tal qual fazia com a filha de Joana. Passados alguns meses, o CT em visita de acompanhamento à residência da família, verificou que a avó de Rafael estava se responsabilizando pelos seus cuidados. Comunicou-se à situação ao Sistema de Justiça e alguns dias depois Rafael foi encaminhado pela Vara da Infância e Juventude (VIJ) a um SFA. Não houve estudo de outros órgãos do SGDCA ou da equipe interprofissional da VIJ.

\footnotetext{
${ }^{5}$ Este caso compõe a pesquisa de doutorado de uma das autoras, aprovada pelo Comitê de Ética e Pesquisa em Ciências Humanas e Sociais da UnB. Destacamos que os nomes são fictícios e que informações que pudessem comprometer o sigilo da pesquisa foram omitidas.
} 
$\mathrm{Na}$ época do acolhimento, Rafael tinha pouco mais de quatro meses. Chegou ao SFA, conduzido pela equipe do comissariado da VIJ e foi recebido pela equipe técnica. A equipe que buscou o bebê na casa da progenitora relatou que no momento da retirada ele estava bem, brincando, limpo e que uma vez que Maiara compreendeu o que se passava, pediu para que eles esperassem que ela faria uma mamadeira e arrumaria uma mala com as roupas de seu neto. Rafael foi levado para uma família acolhedora e a equipe técnica deu início ao estudo psicossocial do caso.

Desde o primeiro contato com a equipe, Maiara demonstrou-se bastante mobilizada com o acolhimento de seu neto, dizia reiteradamente não compreender os motivos que levaram ao acolhimento e afirmava que tudo era culpa de um determinado conselheiro tutelar, com quem ela havia tido um desafeto um tempo antes. Apesar disso, ela se mostrou aberta a dialogar com a equipe e logo iniciou o processo de visitas ao neto na sede do SFA.

Em um momento inicial não houve contato entre a família acolhedora e Maiara. Esta em especial se dizia desconfortável em conhecer os acolhedores e reiterava ter receio de que quisessem tomar seu neto para eles. Sempre comentava que Rafael estava limpo, cheiroso e bem cuidado, mas inicialmente a equipe percebia que ela interpretava este zelo com certa insegurança.

Paralelamente à visita iniciou-se um processo de diálogo com os equipamentos da localidade em que a família de Rafael morava, bem como com seus vizinhos e alguns membros da igreja que frequentavam. Notou-se uma maior resistência do CT em enxergar uma figura protetiva em Maiara, mas em contraponto a isso, os demais órgãos, em especial a rede de saúde e de educação a descreviam como uma mãe zelosa e participativa na vida de seus filhos. Pouco a pouco, à medida que a equipe se fazia mais presente no território, e estabelecia uma relação de confiança tanto com Maiara, como com seus filhos e outras pessoas de importância para a família, algumas situações de fragilidade e vulnerabilidade começaram a ser narradas.

A primeira delas era relacionada à situação de saúde mental de Jaci. Os vizinhos relataram que as crises de Jaci eram muito severas e difíceis de controlar, e que em alguns momentos a jovem era agressiva e que isso poderia colocar as crianças que moravam na casa em risco, uma vez que a própria Maiara tinha dificuldades em gerir essas situações. Após ser questionada algumas vezes sobre essa experiência, Maiara 
começou a falar sobre sua dificuldade de acesso à rede de saúde mental, bem como sobre seus sentimentos em relação à doença da filha e ao impacto que isso causava em sua vida. Pode admitir-se sozinha e desemparada, e em alguns momentos refém de sua própria condição, pois com as crises de Jaci tinha dificuldades de arrumar um emprego, já que não poderia deixar os filhos mais novos e o neto sozinhos com ela, dessa forma contava com os auxílios governamentais e com o suporte financeiro de sua filha Joana.

Após alguns meses de acolhimento, com a ampliação da periodicidade e do tempo das visitas, Maiara começou a falar sobre sua relação com o álcool. Admitiu aos poucos sobre a frequência do uso, e sobre sua dificuldade de adesão à proposta do Centro de Atenção Psicossocial/Álcool e Drogas (CAPSad) ao qual estava referenciada. A equipe técnica precisou nesse momento ser mais incisiva em relação à essa adesão ou a outro modelo de tratamento, mas falou franca e abertamente sobre as consequências do alcoolismo e os riscos que isso apresentava aos seus filhos e neto.

Dois meses após o acolhimento, Maiara e a família acolhedora manifestaram que gostariam de se conhecer, a equipe técnica avaliou que tal encaminhamento teria ganhos importantes e promoveu o encontro. Frisamos, que estes encontros só são proporcionados caso haja disponibilidade mútua entre famílias e avaliação da equipe técnica do serviço a esse respeito. Luana, família acolhedora, pode falar à Maiara sobre a admiração que nutria por seu esforço e perseverança e o quanto sua trajetória para reaver o neto a emocionava. Disse também que se sentia muito honrada em poder cuidar de um bebê tão querido e que dizia a ele sempre que em breve estaria com a avó. Durante todo o encontro, Rafael sorriu e brincou com a avó e com Luana, demonstrava, dentro daquilo esperado para sua idade, estar feliz e confortável com a presença das duas.

Esse encontro foi muito mobilizador para Maiara, que começou a participar de encontros dos Alcoólatras Anônimos (AA) e levava os comprovantes ao CAPSad para que isso constasse em seu prontuário. Compareceu às reuniões marcadas pelo CT e, por fim, passou a relatar e a pedir ajuda à equipe do serviço sobre algumas situações nas quais sentia-se sozinha ou sem saber como proceder. Essa maior aproximação possibilitou que ela fosse encaminhada a um processo psicoterápico, e que a equipe técnica do serviço junto com o Núcleo de Saúde na Família (NASF) encaminhasse Jaci ao equipamento de saúde mental de referência e que se articulasse junto ao órgão de educação vaga na 
modalidade creche para Rafael, e em modalidade integral para as demais crianças, de forma a facilitar o retorno de Maiara ao mercado de trabalho.

Perto da liberação judicial de Rafael, Maiara perguntou à Luana se ela gostaria de ser madrinha do bebê. Dessa maneira, elas estreitaram laços, e a disputa por Rafael, que em algum momento se estabeleceu no pensamento de sua progenitora, findou-se. Agora ela poderia confiar em Luana, enquanto alguém que a respeitava e que zelava pelo seu neto, ou seja, mais um ponto de apoio com quem contar em possíveis momentos de dificuldade.

O acompanhamento pós-reintegração de Rafael e Maiara, por parte do SFA, se estendeu durante um ano. Foi enviado relatório para a VIJ, mediante solicitação desta, após seis meses. Maiara passou a entrar em contato com a equipe do serviço e outros órgãos da rede de proteção local quando se percebia em um momento de dificuldade, e isso possibilitava que medidas preventivas fossem tomadas. Sua capacidade de pedir ajuda passou a ser uma potencialidade, e não mais uma fraqueza como ela compreendia inicialmente. Informou à equipe do SFA que houve visita da VIJ cerca de oito meses após o desacolhimento, o que indicou a realização de um estudo psicossocial.

Maiara mantém contato com a equipe do serviço e em algumas situações participa das turmas de formação de famílias acolhedoras. Em sua fala comparece a experiência do acolhimento de Rafael como a mais difícil de sua vida, que em um determinado momento quase a levou a desistir (referindo-se a bebida), mas que por outro lado foi um período de intenso aprendizado sobre seus limites, seus direitos e a importância de ter pessoas com quem contar, e que isso não a inferiorizava ou depreciava enquanto mulher, mãe ou avó.

\section{CONSIDERAÇÕES FINAIS}

Acolher uma criança/adolescente é acolher sua história e família. Compreender seus vínculos de pertencimento, o lugar e os significados que ocupam nas relações e de que maneira se constituem psiquicamente. Assim, narrativas atravessadas por violações de direito sofrem impactos e desdobramentos que precisam ser enxergados e cuidados de forma cautelosa e respeitosa. É comum nos casos de afastamento familiar, a família 
também ser vítima da violência estrutural, e muitas vezes, não ter compreensão ou dimensão da gravidade e dos significados daquelas vivências.

Um serviço de acolhimento que atua nos casos de forma integrada à rede socioassistencial e considerando cada criança e família em sua singularidade tem maiores possibilidades de atuar de maneira protetiva, respeitosa e ao mesmo tempo transformadora junto aos núcleos familiares e a rede. O próprio SFA (tanto corpo técnico como acolhedores) pode fazer-se rede para aquela família, como no caso relatado no qual a acolhedora passou a compor a rede primaria de Maiara. Isso é possível a partir de uma construção metodológica atenta às armadilhas da repetição de modelos higienistas em relação às famílias atendidas, e aos próprios preconceitos que cada indivíduo pode carregar consigo, uma vez que somos socializados dentro de uma lógica patriarcal e capitalista.

O caso de Rafael ilustra como crenças, valores e preconceitos podem interferir na atuação da rede, e de que forma vivências pessoais comparecem no cotidiano de atuação. Maiara precisou (re)construir a confiança na atuação do Estado, para permitirse ser atendida por seus atores. Por sua vez, os operadores do SGDCA precisaram abrirse para os significados que circulavam naquela família para construir com ela as contingências que se faziam necessárias ao retorno de Rafael.

A confiança de Luana no trabalho delineado pela equipe do SFA permitiu que ela se relacionasse com Maiara e esse contato foi constituidor para Rafael, que percebeu suas figuras de referência afetiva em contato e sentiu-se seguro com isso. Da mesma forma, Maiara e Luana puderam fortalecer-se mutuamente em suas experiências pessoais e a partir disso construíram uma relação saudável e importante para ambas. Maiara passou a ter mais alguém compondo sua rede de apoio e Luana teve sua vinculação com Rafael mantida, respeitada, e ampliada a todo núcleo familiar.

O SFA é uma política pública que contempla em seu formato a complexidade da população atendida ao fazer a defesa da singularidade e do afeto como formas de atuação junto à infância. Concretiza a corresponsabilização pela garantia dos direitos da infância ao convocar a sociedade civil a exercer esse dever constitucional e, dessa forma nos mobiliza a pensar no potencial que cuidados e vínculos de qualidade têm nos processos de desenvolvimento humano, em todas as fases da vida, transformando e 
propiciando novas vivências às crianças, adolescentes, suas famílias, as famílias acolhedoras, a equipe técnica do SFA e, de certa maneira, a todo SGDCA.

\section{REFERÊNCIAS}

AGUIAR, Gabriela Medeiros Rodrigues de; MARTINS, Karla Patrícia Holanda; ROSA, Miriam Debieux. Criança, família e acolhimento institucional: entre a norma e a constituição psíquica. Configurações. Revista Ciências Sociais, n. 23, p. 90-104, 2019.

ARANTES, Esther Maria de M. De "criança infeliz" a "menor irregular"vicissitudes na arte de governar a infância. Mnemosine, 2004.

BAPTISTA, Rachel Fontes; DARÓS, Lindomar; ZAMORA, Maria Helena. Reintegração no contexto do Acolhimento Familiar: um estudo de caso. Brazilian Journal of Health Review, v. 2, n. 3, p. 1788-1814, 2019.

BAPTISTA, Rachel; ZAMORA, Maria Helena; BITTENCOURT, Maria Inês. Deixando de ser o Menino do Lixão: cuidados em família acolhedora. Trivium-Estudos Interdisciplinares, v. 9, n. 1, p. 62-73, 2017.

BRASIL. Decreto no 17.943-A de 12 de outubro de 1927. Consolida leis de assistencia e protecção a menores. Revogado pela Lei no 6.697.

Conselho Nacional dos Direitos da Criança e do Adolescente (Conanda); Conselho Nacional de Assistência Social (CNAS). Resolução Conjunta no ${ }^{1}$, de 18 de junho de 2009. Aprova o documento Orientações Técnicas: Serviços de Acolhimento para Crianças e Adolescentes. Brasília, 2009

. Lei $n$ o 6.697, de 10 de outubro de 1979. Institui o Código de Menores. Revogada pela Lei no 8.069, de 1990.

. Constituição da República Federativa do Brasil de 1988. Brasil; Casa Civil. . Lei no 12.010, de 3 de Agosto de 2009. Dispõe sobre adoção; altera as Leis nos 8.069, de 13 de julho de 1990 - Estatuto da Criança e do Adolescente, 8.560, de 29 de dezembro de 1992; revoga dispositivos da Lei no 10.406, de 10 de janeiro de 2002 - Código Civil, e da Consolidação das Leis do Trabalho - CLT, aprovada pelo Decreto-Lei no 5.452, de 10 de maio de 1943; e dá outras providências; Presidência da República. Casa Civil. Subchefia para Assuntos Jurídicos.

. Lei no 8.742, de 7 de dezembro de 1993. Dispõe sobre a organização da Assistência Social e dá outras providências. Lei no 8069, de 13 de julho de 1990. Estatuto da Criança e do Adolescente.

BRASIL. Presidência da República. Secretaria Especial dos Direitos Humanos. Conselho Nacional dos Direitos da Criança e do Adolescente. Plano Nacional de Promoção, Proteção e Defesa do Direito de Crianças e Adolescentes à Convivência Familiar e Comunitária Brasília, DF: CONANDA, 2006 
CONSELHO NACIONAL DE ASSISTÊNCIA SOCIAL [CNAS]. Resolução CNAS no 23, de 27 de setembro de 2013. Aprovação dos critérios de elegibilidade e partilha dos recursos para expansão qualificada e reordenamento dos Serviços de Acolhimento para crianças, adolescentes e jovens no âmbito dos estados e municípios. Brasília: CNAS, 2013.

DE OLIVEIRA AVELINO, Denise Andreia; BARRETO, Maria de Lourdes Mattos. A família acolhedora e a política pública: um modelo em avaliação. Oikos: Família e Sociedade em Debate, v. 26, n. 1, p. 143-173, 2015.

DELAP, E.; WEDGE, J. Diretrizes para reintegração familiar de crianças e adolescentes . Foundation, 2016.

DOS SANTOS LOPES, Analú; DAL PRÁ, Keli Regina. A previsão da articulação da rede socioassistencial a partir dos dispositivos normativos legais da Assistência Social. Sociedade em Debate, v. 26, n. 3, p. 110-130, 2020.

FERNANDES JACOBINA, Laís; LEMOS DE PAIVA, Ilana. "Aconchego do Lar»: Discutindo o Serviço de Acolhimento Familiar. Revista Latinoamericana de Ciencias Sociales, Niñez y Juventud, v. 18, n. 1, p. 43-65, 2020.

GARCIA, Joana. Apontamentos sobre a controvertida centralidade da família no trabalho social. SER Social, Brasília, v.20, n.42, jan./jun.2018.

GARCIA, Joana; LIMA, Carlos. A doutrina de proteção integral em contraste com práticas de abandono. Argumentum, v. 12, n. 1, p. 67-81, 2020.

GONÇALVES, Antônio Sérgio; GUARÁ, Isa Maria F. Rosa. Redes de proteção social na comunidade. In: GUARÁ, Isa Maria F. Rosa. Redes de proteção social. São Paulo: Associação Fazendo História: NECA; Associação dos Pesquisadores de Núcleos de Estudos e Pesquisas sobre a Criança e o Adolescente, 2010.

MASTROIANNI, Fábio de Carvalho et al. (Des) acolhimento institucional de crianças e adolescentes: aspectos familiares associados. Fractal: Revista de Psicologia, v. 30, p. 223-233, 2018.

NAKAMURA, Carlos Renato. Criança e adolescente: sujeito ou objeto da adoção? Reflexões sobre menorismo e proteção integral. Serviço Social \& Sociedade, n. 134, p. 179-197, 2019.

NASCIMENTO, Maria Livia do. Abrigo, pobreza e negligência: percursos de judicialização. Psicologia \& Sociedade, v. 24, p. 39-44, 2012.

OLIVEIRA, Ana Paula Polacchini de et al. O direito de crianças e adolescentes à convivência familiar e comunitária: diálogos entre direito positivo, história, cinema e literatura. Direito e Sociedade: Revista de Estudos Jurídicos e Interdisciplinares, v. 13, n 01 p. 27-40, 2018.

PATIAS, Naiana Dapieve; GARCIA, Narjara Mendes; DELL'AGLIO, Débora Dalbosco. Imagens sociais sobre famílias com filhos em instituição de acolhimento. 
Revista Interamericana de Psicología/Interamerican Journal of Psychology, v. 50, n. 2, p. 215-224, 2016.

RIZZINI, Irene; RIZZINI, Irma. A institucionalização de crianças no Brasil: percurso histórico e desafios do presente. Rio de Janeiro: Ed. PUC-Rio; SãoPaulo: Loyola,2004.

SANÍCOLA, L. As dinâmicas de rede e o trabalho social Tradução Durval Cordas. São Paulo: Veras Editora, 2008.

VALENTE, Jane. Família Acolhedora. As relações de cuidado e proteção no serviço de acolhimento. São Paulo, 2013.

WENDT, Bruna et al. Imagens sociais atribuídas às instituições de acolhimento. Revista da SPAGESP, v. 19, n. 1, p. 35-48, 2018. 